\title{
Gender difference on the development of metabolic syndrome: a population-based study in Taiwan
}

\author{
Lee-Ching Hwang · Chyi-Huey Bai • \\ Chien-Jen Chen $\cdot$ Kuo-Liong Chien
}

Received: 27 July 2006/ Accepted: 12 September 2007/Published online: 10 October 2007

(C) Springer Science+Business Media B.V. 2007

\begin{abstract}
Little is known regarding the development of metabolic syndrome. This study examining gender difference in the characteristics of metabolic components aimed to estimate the development of metabolic syndrome in both genders. This nation-wide, population-based survey included 5,880 men and women aged 20-79 years in Taiwan. Metabolic syndrome was defined by the revised National Cholesterol Education Program Adult Treatment Panel III, with adoption of the Asian criteria for abdominal obesity. The results indicate that metabolic syndrome was prevalent in $20.4 \%$ of the men and $15.3 \%$ of the women. Lipid components occurred the earliest in both genders. The appearance of the first isolated component was earlier in women than in men (mean age 43.4 vs. 45.6 years, $P<0.05)$. In contrast, the mean prevalent age of metabolic syndrome appeared earlier in men than in women by
\end{abstract}

L.-C. Hwang

Department of Family Medicine, Mackay Memorial Hospital, Taipei, Taiwan, ROC

\section{L.-C. Hwang}

Department of Nursing, Mackay Medicine, Nursing

and Management College, Taipei, Taiwan, ROC

\section{C.-H. Bai}

Central Laboratory, Shin Kong WHS Memorial Hospital, Taipei, Taiwan, ROC

\section{C.-J. Chen $(\bowtie)$}

Graduate Institute of Epidemiology, College of Public Health, National Taiwan University, No. 1 Jen-Ai Road Section 1,

Taipei 10018, Taiwan, ROC

e-mail: cjchen@ntu.edu.tw

\section{K.-L. Chien}

Institute of Preventive Medicine, College of Public Health, National Taiwan University, Taipei, Taiwan, ROC
4.9 years (mean age 51.3 vs. 56.2 years, $P<0.05$ ). The differences in prevalent age from the appearance of any isolated component to metabolic syndrome were 12.8 years in women and 5.7 years in men, respectively. If men had a body mass index less than $23 \mathrm{~kg} / \mathrm{m}^{2}$ and exercise habits, the difference in the prevalent age from the isolated component to metabolic syndrome was 15.4 years, longer than for all women subjects. We conclude lipid components appeared the earliest. Women had the first isolated component earlier, presenting as metabolic syndrome later than men. The development of metabolic syndrome was slower in subjects without overweight characteristics and with exercise habits.

Keywords Body mass index - Exercise · Gender difference $\cdot$ Metabolic syndrome

\section{Introduction}

The metabolic syndrome (MetS), a cluster of central obesity, glucose intolerance, hypertension, and dyslipidemia $[1,2]$, poses for risks of cardiovascular diseases and 
diabetes mellitus [3, 4]. There is a significant gender difference in cardiovascular diseases risks, showing a male to female ratio of 2-5 [5, 6]. MetS has been observed in many ethnic groups [7-13], and the influence of gender on its prevalence varies between populations mainly related to the characteristics of the population sampled and its definition. In Asian countries, studies revealed that the prevalence of MetS is higher among men than among women in Singapore [8, 9], Korea [10] and Taiwan [11] according to the modified National Cholesterol Education Program Expert Panel Adult Treatment Panel III (NCEP ATP III) criteria [9]. Among young and middle-aged adults, women have lower blood pressure and serum levels of triglyceride, and less abdominal fat accumulation than men [14]. However, the protection conferred on women is not lifelong and the prevalences of MetS increased with age especially in women, sharply beyond aged 50-60 years [7, 11]. Recent studies indicate that the programming of metabolic disorder and the process of atherosclerosis starts at an early age, show differences on gender [15]. However, few literatures discussed or assessed the natural history of MetS but that is important to design intervention strategies. The effectiveness of lifestyle modification, changes in diet and physical activity in the resolution of MetS, was demonstrated [16] and that illustrated the importance of taking intervention to prevent disease progression. In the effort to examine gender difference in the characteristics of metabolic components aimed at different preventive strategies, this study was designed with the aim to assess gender differences in the development of MetS, and the influence of exercise habits and overweight characteristics on these differences.

\section{Methods}

\section{Population surveys}

We utilized data from a nation-wide, cross-sectional, population-based survey, named the Taiwanese Survey on Prevalence of Hyperglycemia, Hyperlipidemia, and Hypertension (TwSHHH) 2002. This study was based on the National Health Interview Survey (NHIS) which employed a multi-staged, stratified, clustering sampling scheme in 2001 (including 26,685 non-institutionalized residents from 6,592 households in 1,648 communities in Taiwan). Half of the NHIS sampled Household Registration List (3,296 households) in each stratum were randomly selected for the TwSHHH. There were 7,578 (attendance rate: $73.6 \%$ ) from 10,292 eligible subjects participated TwSHHH. The details of this population have been described previously [17]. All participants gave written informed consent. Subjects who lacked a blood specimen (976 participants) or who were older than 80-year old or less than 20-year old were excluded. The remaining 5,880 subjects were included in the following analyses. No significant differences were found in the prevalence of metabolic disorders between study subjects and excluded subjects.

\section{Data collection}

Socio-demographic characteristic data including gender, age, personal habits, family history of cardiovascular related diseases, physician-diagnosed diseases and medication history were investigated using a trained-nurseadministrated questionnaire. Sitting blood pressure (BP) and anthropometrical measurements were measured. Two $\mathrm{BP}$ measurements were made $30 \mathrm{~s}$ apart in the right arm after the participant sat and rested for 5-10 min. A third BP measurement was made when the first two BP readings differed by more than $10 \mathrm{mmHg}$. The average of the two closest readings was calculated and used in the analysis. Waist circumference (WC) was measured at the narrowest point with a tape measure placed parallel to the floor. $\mathrm{NaF}$ plasma was collected for fasting plasma glucose (FPG) analysis, along with serum for levels of lipids. Blood samples were transported in dry-ice to the central laboratory, stored at $-20^{\circ} \mathrm{C}$ and analyzed within 2 weeks. Fasting triglyceride (TG) (Bucolo method) and FPG (glucose oxidase method) were measured by an automated system (Vitros 550/750, Johnson \& Johnson, USA). High-density lipoprotein cholesterol (HDL) was measured by electrophoresis. Body mass index (BMI) was calculated as weight in kilograms divided by the square of the height in meters. We adopted the BMI cutoffs suggested by the World Health Organization Asian Pacific Guideline for classification of excess weight [18]. Accordingly, subjects were classified into normal (BMI $<23)$, overweight $(23 \leq$ BMI $<25)$ or obese (BMI $\geq 25)$ categories. Smoking was categorized as current, past, and never during the previous 3 months. Alcohol drinking status was categorized as frequent (more than once a week), less frequent (less than once a week), and never. Exercise habits was defined as regularly exercising for over 30 min during the previous 3 months and categorized as frequent (more than twice a week), less frequent (once a week), and never.

\section{Criteria of MetS and its components}

Revised NCEP ATP III diagnostic criteria have been approved by the American Heart Association in 2005 [2]. The definition of central obesity was modified as a WC more than $90 \mathrm{~cm}$ in men, and more than $80 \mathrm{~cm}$ in women [18]. Based on this revised NCEP ATP III for Asians definition, we defined MetS as needing at least three out of 
five of the following criteria: (1) $\mathrm{WC} \geq 90 \mathrm{~cm}$ in men or $80 \mathrm{~cm}$ in women; (2) fasting $\mathrm{TG} \geq 1.69 \mathrm{mmol} / \mathrm{l}$; (3) $\mathrm{HDL}<1.03 \mathrm{mmol} / 1$ in men or $<1.29 \mathrm{mmol} / 1$ in women; (4) systolic $\mathrm{BP} \geq 130 \mathrm{mmHg}$ or diastolic $\mathrm{BP} \geq 85 \mathrm{mmHg}$, or current use of antihypertensive drugs; and (5) FPG $\geq$ $5.6 \mathrm{mmol} / \mathrm{l}$ or current use of antidiabetic drugs.

\section{Statistical analysis}

We expressed the prevalence of the individual component of MetS as proportions and compared those between genders by a chi-square test. A graphical presentation of gender-specific prevalence rates for MetS and its components are provided in 5-year increments.

The prevalent age of individual component is shown as the mean age and its standard deviation $(S D)$. Differences of mean prevalent age between genders in individual component were tested using analysis of a general linear model after adjustment for exercise habits, smoking and alcohol drinking status. The term, isolated component, was defined as participants having only one component of MetS. The gender impacts on prevalent age difference from having isolated component to fulfilling the criteria of MetS were assessed by two sample $t$ test by a SUDAAN descript procedure that tests the differences of two means from two data sets [19]. The statistical analyses were performed with a SAS statistical software (version 8.2; SAS Institute), and survey software SUDDAN was used (survey procedures in SAS) to correct the affection by sample weight. Statistical significance was designated at $P<0.05$ and an odds ratio that excluded 1.

\section{Results}

Characteristics of the study subjects

Among the 5,880 subjects with a mean age of 44.7 (SD 15.0) years, MetS that was defined with the revised NCEP ATP III for Asians definition was prevalent in $20.4 \%$ of the men and $15.3 \%$ of the women (Table 1). Men had higher mean values of TG concentration, BMI, systolic and diastolic BP, and a higher prevalence of current smoking, current alcohol drinking, and overweight characteristics $(P<0.0001)$ than women.

Subjects who were physically inactive accounted for $46.5 \%$. There were no differences between men and women. In components of MetS, high BP (34.1\%) was the most common component in men, followed by high TG $(32.6 \%)$ and large WC (27.7\%). However, the component of a large WC $(29.2 \%)$ was the most common risk factor in women, followed by the component of low HDL (25.4\%).
A higher prevalence of high BP, high TG and high FPG were noted in men than in women.

Gender difference in the prevalence of individual components and MetS

The prevalence of a large WC, high BP and high FPG increased with age in both genders, whereas the prevalence of a low HDL differed little between categories of age groups (Fig. 1). The distribution of these metabolic abnormalities on age groups differed in gender. Men aged less than 50 years had a higher prevalence of a large WC, high TG, high BP and high FPG than women. In contrast, the prevalence of these components rose sharply after the menopausal transition. The prevalence of a large WC in women after the menopausal period increased rapidly and was higher than in men beyond the age group of 50-55. Therefore, the prevalence of MetS was lower in women than men until after age 50 years, although showing a cross over beyond the age group of 50-59 years, becoming higher in women.

Gender difference in the prevalent age of individual components and MetS

We computed the prevalent age of individual components and its combination with other components, shown in Table 2. Regardless of gender difference, low HDL was present in the youngest mean age, followed by high TG. Lipid components of MetS occurred the earliest, compared with other nonlipid components.

The appearance of the first individual component showed earlier in women than in men (mean age: 43.4 vs. 45.6 years, $P<0.05$ ). In contrast, the mean age of MetS showed earlier in men than in women by 4.9 years (mean age: 51.3 vs. 56.2 years, $P<0.05$ ).

The difference in the prevalent age from the appearance of any isolated component to MetS was 12.8 years in women and 5.7 years in men. Regardless of which component was present, men were sooner than women in presenting as cases of MetS. The difference in the prevalent age from having the first isolated component to fulfilling MetS (more than three components) varied. There were greater years between the prevalent age of isolated low HDL and MetS with low HDL components in women than in men (20.3 years in women, 12.1 years in men, respectively). However, the differences in prevalent age from isolated high BP to MetS with high BP were 5.1 years in women and 1.7 years in men.

In both genders, overweight characteristics and physical inactive subjects took fewer years to present MetS. If men 
Table 1 Basic characteristics of the study sample

\begin{tabular}{|c|c|c|c|c|}
\hline & Total subjects $(n=5,880)$ & $\operatorname{Men}(n=2,775)$ & Women $(n=3,105)$ & $P$ \\
\hline Age (years) & $44.7(15.0)$ & $45.0(14.7)$ & $44.3(15.4)$ & 0.073 \\
\hline Body mass index $\left(\mathrm{kg} / \mathrm{m}^{2}\right)$ & $23.7(3.7)$ & $24.3(3.5)$ & $23.0(3.8)$ & $<0.0001$ \\
\hline Waist circumference $(\mathrm{cm})$ & $80.5(10.9)$ & $85.2(9.8)$ & $76.2(10.0)$ & $<0.0001$ \\
\hline Systolic blood pressure (mmHg) & $115.9(18.1)$ & $119.3(16.6)$ & $112.9(18.9)$ & $<0.0001$ \\
\hline Diastolic blood pressure $(\mathrm{mmHg})$ & $75.4(11.3)$ & $78.4(10.9)$ & $72.8(10.9)$ & $<0.0001$ \\
\hline Fasting plasma glucose (mmol/l) & $5.27(1.63)$ & $5.31(1.64)$ & $5.25(1.62)$ & 0.1326 \\
\hline Triglycerides (mmol/1) & $1.48(0.98)$ & $1.68(1.10)$ & $1.30(0.82)$ & $<0.0001$ \\
\hline HDL cholesterol (mmol/l) & $1.44(0.39)$ & $1.34(0.39)$ & $1.53(0.37)$ & $<0.0001$ \\
\hline \multicolumn{5}{|l|}{ Medical treatment } \\
\hline Antihypertensive agent $(\%)$ & 10.8 & 11.1 & 10.4 & 0.3870 \\
\hline Lipid-lowering drugs $(\%)$ & 4.1 & 4.5 & 3.7 & 0.1378 \\
\hline Antidiabetes drugs (\%) & 3.8 & 4.0 & 3.7 & 0.5121 \\
\hline \multicolumn{5}{|l|}{ Overweight and obesity (\%) } \\
\hline Body mass index $\left(\mathrm{kg} / \mathrm{m}^{2}\right)$ 23-24.9 & 21.6 & 24.5 & 18.9 & \multirow[t]{2}{*}{$<0.0001$} \\
\hline Body mass index $\left(\mathrm{kg} / \mathrm{m}^{2}\right) \geq 25$ & 31.6 & 37.9 & 25.6 & \\
\hline \multicolumn{5}{|l|}{ Smoking (\%) } \\
\hline Current smoker & 23.3 & 45.2 & 3.7 & \multirow[t]{3}{*}{$<0.0001$} \\
\hline Ex-smoker & 3.9 & 7.8 & 0.4 & \\
\hline Never & 72.9 & 47.0 & 95.9 & \\
\hline \multicolumn{5}{|l|}{ Alcohol drinking $(\%)$} \\
\hline Frequent, $\geq$ once a week & 12.3 & 22.0 & 3.6 & \multirow[t]{3}{*}{$<0.0001$} \\
\hline Less frequent, <once a week & 14.1 & 21.6 & 7.4 & \\
\hline Never & 73.6 & 56.4 & 89.0 & \\
\hline \multicolumn{5}{|l|}{ Exercise habits $(\%)$} \\
\hline Frequent, $\geq$ twice a week & 35.1 & 34.1 & 37.1 & \multirow[t]{3}{*}{0.001} \\
\hline Less frequent, once a week & 17.1 & 19.1 & 15.9 & \\
\hline Never & 47.8 & 46.8 & 47.0 & \\
\hline Low HDL cholesterol level ${ }^{\mathrm{a}}(\%)$ & 23.4 & 21.7 & 24.8 & 0.0045 \\
\hline High TG level ${ }^{\mathrm{b}}(\%)$ & 27.5 & 35.2 & 20.7 & $<0.0001$ \\
\hline Large $\mathrm{WC}^{\mathrm{c}}(\%)$ & 30.0 & 29.2 & 30.6 & 0.2411 \\
\hline High $\mathrm{FPG}^{\mathrm{d}}(\%)$ & 18.5 & 19.6 & 17.4 & 0.0314 \\
\hline High $\mathrm{BP}^{\mathrm{e}}(\%)$ & 29.7 & 36.3 & 23.7 & $<0.0001$ \\
\hline
\end{tabular}

${ }^{\mathrm{a}}$ Low high-density lipoprotein $<1.03 \mathrm{mmol} / 1$ in men or $<1.29 \mathrm{mmol} / 1$ in women

b High triglyceride level $\geq 1.69 \mathrm{mmol} / \mathrm{l}$

c Large waist circumference $\geq 90 \mathrm{~cm}$ in men, $\geq 80 \mathrm{~cm}$ in women according to Asian criteria

d High fasting plasma glucose level ( $\geq 5.6 \mathrm{mmol} / \mathrm{l})$ or taking medication

e High blood pressure $(\geq 130 / 85 \mathrm{mmHg})$ or taking medication

had BMI less than $23 \mathrm{~kg} / \mathrm{m}^{2}$ and exercised more than once a week, the differences in the prevalent age from the first isolate component to MetS was 15.4 years, longer than for all women subjects (Table 3).

\section{Discussion}

We found in the present study that MetS, as defined with the revised NCEP ATP III, for Asians definition, was prevalent in $20.4 \%$ of the men and $15.3 \%$ of the women.
The prevalence of MetS was lower in women than in men until after age 50, also showing a crossover. Lipid components of MetS occurred the earliest in both genders, whereas high BP was seen in the oldest. Women had the first isolated component earlier and presented as cases of MetS later than in men. We found that the development of MetS was slower in subjects without overweight characteristics and with exercise habits.

The influence of gender on the prevalence of MetS varies between populations. In Taiwan, previous studies demonstrated a higher prevalence of MetS in men than in 


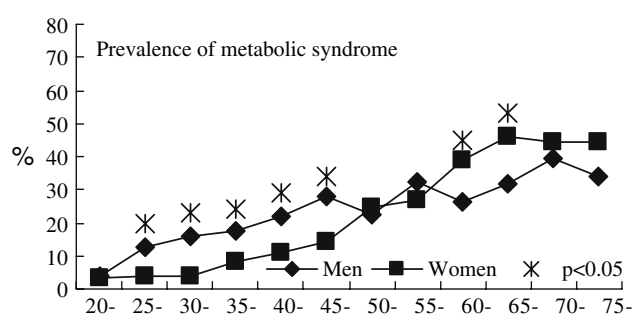

(y)

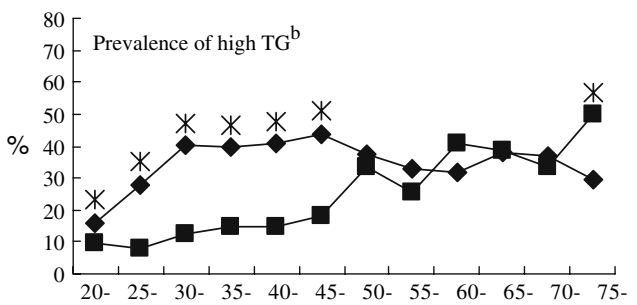

(y)

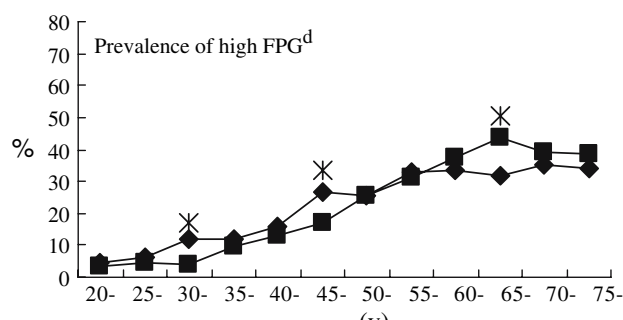

(y)

Fig. 1 The gender-age-specific prevalence of metabolic syndrome and it components in men and in women. (a) Low high-density lipoprotein $<1.03 \mathrm{mmol} / 1$ in men or $<1.29 \mathrm{mmol} / 1$ in women, (b) high triglyceride level $\geq 1.69 \mathrm{mmol} / 1$, (c) large waist

women $(15.5-29.2 \%$ in men and $4.8-10.5 \%$ in women according to modified NCEP ATP III definition, respectively) $[11,20]$. Compared with the modified NCEP ATP III definition of MetS, we found similar prevalence rates in men, but higher prevalence rates in women with the revised NCEP ATP III for Asians definition. The influence on the prevalence of MetS was greater in women than in men. Reports from the US National Health and Nutrition Examination Survey [7] and from a study of a large health check-up population in Taiwan [11] also demonstrated this reversal of MetS prevalence by sex after an age of 60 years. In this cross-sectional survey, we found that the distribution of these components of MetS on age groups differed in gender. Prevalence of MetS was higher in men than in women before the age group of 50 years, which was attributable to higher prevalent of high TG and high BP components in men. Prevalence of MetS was higher in women than in men beyond the age group of 60 years, because large WC component increased rapidly with age in women after the menopausal period.

It is difficult to establish the cascade of components that characterize the syndrome. As such, the development of MetS has not been clarified clearly. Earlier appearances of

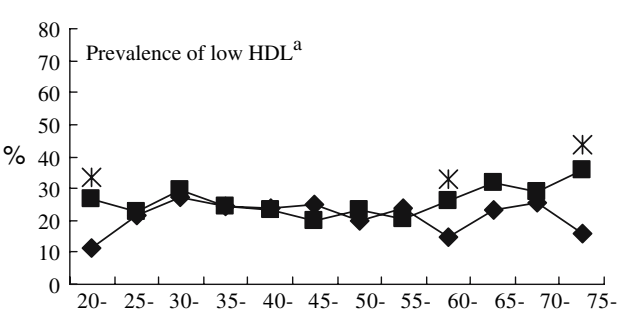

(y)

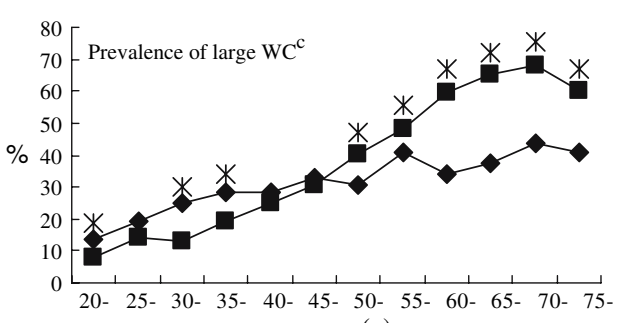

(y)

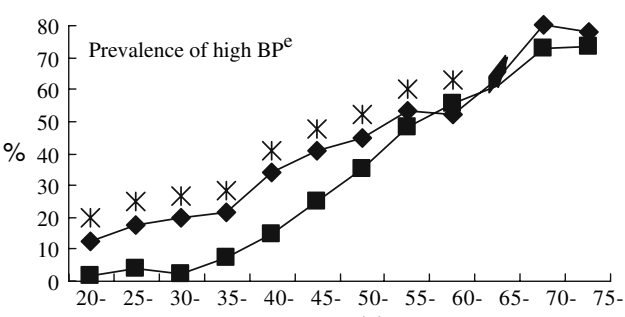

(y)

circumference $\geq 90 \mathrm{~cm}$ in men, $\geq 80 \mathrm{~cm}$ in women according to Asian criteria, (d) high fasting plasma glucose level $(\geq 5.6 \mathrm{mmol} / \mathrm{l})$ or taking medication, (e) high blood pressure $(\geq 130 / 85 \mathrm{mmHg})$ or taking medication

lipid components with a higher prevalence in younger age groups indicate that dietary fat intake contributes to the positive associations of MetS [21]. In this study, although adiposity was also positively associated with dietary fat intake, appearance of lipid components was close to approaching the large WC cut-off point in this study.

We detected gender-related influences on the prevalent age at presenting components of MetS and found that the appearance of the first isolated component showed earlier in women than in men by 2 years. The difference in prevalent age from appearance of any isolated component to MetS was 12.8 years in women and 5.7 years in men. Women had the first isolated component earlier and presented as cases of MetS later than men. The strength of the observed difference of prevalent age on gender might be dependent on the cut-off point for these metabolic components. It can be argued that the cut-off points are arbitrary (with lower levels of large WC and higher levels of low HDL criteria of MetS in women), and the proportion of high-risk individuals would have risen considerably. In this study, we applied men's criteria to women and found that the difference in prevalent age from appearance of any isolated component to MetS was 9.4 years in women. 
Table 2 Mean prevalent age of individual or combined components of metabolic syndrome in 2,775 men and 3,105 women and comparison on gender differences ${ }^{\mathrm{a}}$

\begin{tabular}{|c|c|c|c|c|c|c|}
\hline & \multicolumn{4}{|c|}{ Mean prevalent age (y) (standard deviation) } & \multirow[t]{3}{*}{$P$-value for trend ${ }^{\mathrm{b}}$} & \multirow{3}{*}{$\begin{array}{l}\text { Difference }(95 \% \mathrm{CI}) \\
\text { from " } \geq 3 \text { " to " } 1 \text { " }\end{array}$} \\
\hline & \multicolumn{4}{|c|}{ Number of individual metabolic component } & & \\
\hline & 0 & 1 & 2 & $\geq 3$ & & \\
\hline \multicolumn{7}{|l|}{ Men } \\
\hline Any type of components & $38.6(13.8)$ & $45.6(15.4)^{*}$ & $47.9(14.9)^{*}$ & $51.3(14.6)^{*}$ & $<0.0001$ & $5.7(4.0-7.3)^{* * *}$ \\
\hline Low HDL choesterol ${ }^{\mathrm{c}}$ group & & $36.8(13.5)$ & $42.4(13.3)$ & $48.9(14.2)^{*}$ & $<0.0001$ & $12.1(8.9-15.5)^{* * * *}$ \\
\hline High TG level $^{\mathrm{d}}$ group & & $39.9(12.4)$ & $44.2(13.7)$ & $49.5(14.2)^{* *}$ & $<0.0001$ & $9.6(7.2-12.1)$ \\
\hline Large $\mathrm{WC}^{\mathrm{e}}$ group & & $43.8(14.6)^{*}$ & $48.3(15.4)^{*}$ & $50.9(14.8)^{*}$ & $<0.0001$ & $7.1(4.2-10.1)^{*}$ \\
\hline High FPG $^{\mathrm{f}}$ group & & $49.4(12.7)$ & $51.8(14.3)^{*}$ & $54.8(13.9)$ & 0.0055 & $5.4(2.1-8.8)^{* *}$ \\
\hline High $\mathrm{BP}^{\mathrm{g}}$ group & & $51.7(16.0)$ & $52.8(15.1)^{*}$ & $53.4(14.4)^{* *}$ & 0.3263 & $1.7(0.6-3.9)^{* *}$ \\
\hline \multicolumn{7}{|l|}{ Women } \\
\hline Any type of components & $37.3(11.1)$ & $43.4(14.0)$ & $51.5(14.2)$ & $56.2(13.2)$ & $<0.0001$ & $12.8(11.3-14.4)$ \\
\hline Low HDL choesterol $^{\mathrm{c}}$ group & & $34.2(10.1)$ & $44.6(13.9)$ & $54.5(14.1)$ & $<0.0001$ & $20.3(18.3-22.3)$ \\
\hline High TG level ${ }^{\mathrm{d}}$ group & & $43.8(13.8)$ & $47.6(14.5)$ & $55.7(13.5)$ & $<0.0001$ & $11.9(8.7-14.9)$ \\
\hline Large $\mathrm{WC}^{\mathrm{e}}$ group & & $46.9(13.4)$ & $52.3(13.9)$ & $56.3(13.5)$ & $<0.0001$ & $9.6(7.2-11.6)$ \\
\hline High $\mathrm{FPG}^{\mathrm{f}}$ group & & $46.6(12.9)$ & $55.5(13.2)$ & $57.4(12.2)$ & $<0.0001$ & $10.8(7.8-13.6)$ \\
\hline High $\mathrm{BP}^{\mathrm{g}}$ group & & $53.8(11.9)$ & $57.0(11.8)$ & $58.9(11.8)$ & $<0.0001$ & $5.1(2.8-7.3)$ \\
\hline
\end{tabular}

\footnotetext{
${ }^{a}$ Significance between genders. NS, not significant; $* P<0.05 ; * * P<0.01 ; * * * P<0.001$

b $P$ for trend by general linear regression with adjustment for smoking, alcohol drinking status and exercise habits

${ }^{\mathrm{c}}$ Low high-density lipoprotein $<1.03 \mathrm{mmol} / \mathrm{l}$ in men or $<1.29 \mathrm{mmol} / \mathrm{l}$ in women

${ }^{\mathrm{d}}$ High triglyceride level $\geq 1.69 \mathrm{mmol} / \mathrm{l}$

e Large waist circumference $\geq 90 \mathrm{~cm}$ in men, $\geq 80 \mathrm{~cm}$ in women according to Asian criteria

${ }^{\mathrm{f}}$ High fasting plasma glucose level $(\geq 5.6 \mathrm{mmol} / \mathrm{l})$ or taking medication

g High blood pressure $(\geq 130 / 85 \mathrm{mmHg})$ or taking medication
}

Table 3 Differences of prevalent age ${ }^{a}$ from having the first isolated component to fulfilling the definition of metabolic syndrome (more than three components) and the influence of $\mathrm{BMI}^{\mathrm{b}}$ and exercise habits

\begin{tabular}{|c|c|c|c|c|c|}
\hline & Total subjects & $\mathrm{BMI} \geq 23$ & $\begin{array}{l}\text { Without exercise } \\
\text { habits }\end{array}$ & $\begin{array}{l}\mathrm{BMI} \geq 23 \text { and without } \\
\text { exercise habits }\end{array}$ & $\begin{array}{l}\text { BMI }<23 \text { and with } \\
\text { exercise habits }\end{array}$ \\
\hline \multicolumn{6}{|l|}{ Men } \\
\hline A. The first isolated component & $45.6(15.4)$ & $44.0(13.0)$ & $44.8(14.4)$ & $43.7(12.7)$ & $49.1(17.8)$ \\
\hline B. More than three components & $51.3(14.6)$ & $49.4(14.2)$ & 48.9 (13.9) & $46.9(13.2)$ & $64.4(11.5)$ \\
\hline Differences $^{\mathrm{c}}$ : $\mathrm{B}-\mathrm{A}$ & $5.7(4.0-7.3)$ & $5.4(3.5-7.2)^{\mathrm{NS}}$ & $4.0(1.8-6.2)^{\mathrm{NS}}$ & $3.2(0.8-5.7)^{* *}$ & $15.4(9.8-20.9)^{* * * *}$ \\
\hline \multicolumn{6}{|l|}{ Women } \\
\hline A. The first isolated component & $43.4(14.0)$ & $43.9(12.2)$ & $42.6(13.9)$ & $42.2(11.4)$ & $43.1(14.9)$ \\
\hline B. More than three components & $56.2(13.2)$ & $53.8(13.2)$ & $54.9(12.9)$ & $52.6(12.8)$ & $62.9(11.7)$ \\
\hline Differences $^{c}$ : B - A & $12.8(11.3-14.4)$ & $9.9(8.1-11.9)^{* * *}$ & $12.3(10.1-14.5)^{\mathrm{NS}}$ & $10.4(7.7-13.2)^{* *}$ & $19.9(16.5-23.4)^{* * *}$ \\
\hline
\end{tabular}

Previous studies reveal that women develop cardiovascular diseases later in life than men, and women are lagging behind men by about $10-15$ years [22, 23]. Cardiovascular gender differences are apparent long before cardiovascular diseases appear in men and women. Insulin resistance appears to be a central feature of MetS. Metabolic control varies between men and women. Intrinsic sexual dimorphisms exist at the molecular and cellular levels and, obviously, there is the presence of different sex steroid hormones [24]. Data of the EarlyBird Study showed 
that girls were intrinsically more insulin resistant than boys [25]. Girls aged 5 years were $30 \%$ more insulin resistant than boys. That could be the one of causes to explain why women had the first isolated component earlier in this study. In contrast, adult men are more insulin resistant than women [26]. Greater visceral fat accumulation and lower plasma adiponectin concentrations in men than women are candidates for mediating gender differences in insulin sensitivity and higher vulnerability to CVD [27, 28]. Among young and middle-aged adults in this study, women have lower BP and TG, and less visceral fat accumulation than men. However, the protection conferred on women is not lifelong, dissipating rapidly after the age of 50 [14]. That supports the protective effects of female sex hormones and the unfavorable effects of testosterone on substrate metabolism in view of the MetS.

The iron depletion effects were also raised to explain the phenomenon of gender differences. Elevated ferritin levels have been associated with MetS. Jehn M et al. conducted a cross-sectional study of 6,044 adults in the US and found that the positive association between elevated iron stores and the prevalence of MetS [29]. Punnonen et al. examined CVD risk after premenopausal hysterectomy or myomectomy and found that the relative risk was three times greater in the hysterectomy group than in the myomectomy group in a period of 11-18 years after the procedures [30]. That study data indicate that a functioning uterus and loss of blood and iron are necessary for continued cardiovascular protection of women.

The discrepancy might be also explained in part by the survivor bias with an earlier average death in men than in women. Previous studies showed men having 2-5 times higher CVD mortality rates than women among middleaged people $[5,6]$. Another limitation of this study is the use of cross-sectional survey to predict the development of metabolic components that might exist birth cohort effects in the population. Further research of cohort follow-up designs would be ideal to understand the gender difference on the development of metabolic syndrome. Nevertheless, we obtained the significant differences of prevalent age of MetS and its components in men and women, which indicate the need for programs of health promotion and high risk screening intervention in the consideration of differences in gender.

In comparison with Caucasians, Asians have a greater risk of fitting the metabolic profile at lower WC than do whites [31]. Ethnic-specific cutoff points of cardiometabolic components in MetS focusing on the definition of abdominal obesity have been suggested [18]. Therefore, the issue of the gender difference on the development of MetS might also need to be discussed according to ethnicspecific conditions.
Current recommendations for managing the cardiovascular disease risk focus on lifestyle modifications that have been shown to be of benefit, particularly in the reduction of excess adiposity and the increase in physical activity [16]. We found that a BMI $<23 \mathrm{~kg} / \mathrm{m}^{2}$ and exercise behavior could lengthen the development of MetS in both genders, but more significantly in men than in women. Previous studies suggested that men gain much more benefit from exercise training than women, whereas women only benefit from it when it is accompanied by weight loss [32]. In intervention studies, exercise training in combination with weight loss improved insulin sensitivity in both genders, whereas men had significantly larger improvements in insulin sensitivity than women in response to an exercisetraining program in the absence of substantial weight loss [33].

A better understanding of these metabolic component changes between aging and gender will aid in the recognition and treatment of subjects at risk for future MetS and cardiovascular diseases, leading to appropriate interventions. Additional clarification of gender difference in the development characteristics of MetS by a cohort study is required, as individuals with this condition are increasingly being considered as candidates for behavioral and pharmacologic intervention.

Acknowledgements We would like to thank all investigators of TwSHHH Project for their contribution to the compilation and validation the data. This study was supported by the Bureau of Health Promotion in Taiwan.

\section{References}

1. Executive summary of the third report of the national cholesterol education program (NCEP) Expert panel on detection, evaluation, and treatment of high blood cholesterol in adults (Adult Treatment Panel III). JAMA 2001;285:2486-97.

2. Grundy SM, Cleeman JI, Daniels SR, Donato KA, Eckel RH, Franklin BA, et al. Disagnosis and management of the metabolic syndrome: an American Heart Association/National Heart, Lung, and Blood Institute Scientific statement. Circulation 2005; 112:2735-52.

3. Lakka HM, Laaksonen DE, Lakka TA, Niskanen LK, Kumpusalo E, Tuomilehto $\mathrm{J}$, et al. The metabolic syndrome and total and cardiovascular disease mortality in middle-aged men. JAMA 2002;288:2709-16.

4. Wilson WF, D'Agostino RB, Parise H, Sullivan L, Meigs JB. Metabolic syndrome as a precursor of cardiovascular disease and type 2 diabetes mellitus. Circulation 2005; 112:3066-72.

5. Jackson R, Chambless L, Higgins M, Kuulasmaa K, Wijnberg L, Williams D. WHO MONICA Project, and ARIC Study Sex difference in ischaemic heart disease mortality and risk factors in 46 communities: an ecologic analysis. Cardiovasc Risk Factors 1997;7:43-54.

6. Jousilahti P, Vartiainen E, Tuomilehto J, Puska P. Sex, age, cardiovascular risk factors, and coronary heart disease: a prospective follow-up study of 14,786 middle aged men and women in Finland. Circulation 1999;99:1165-72. 
7. Ford ES, Giles WH, Dietz WH. Prevalence of the metabolic syndrome among US adults findings from the Third National Health and Nutrition Examination Survey. JAMA 2002;287: $356-9$.

8. Ang LW, Ma S, Cutter J, Chew SK, Tan CE, Tai ES. The metabolic syndrome in Chinese, Malays and Asian Indians. Factor analysis of data from the 1998 Singapore National Health Survey. Diabetes Res Clin Pract 2005;67:53-62.

9. Tan CE, Ma S, Wai D, Chew SK, Tai ES. Can we apply the National Cholesterol Education Program Adult Treatment Panel definition of the metabolic syndrome to Asians? Diabetes Care 2004;27:1182-6.

10. Oh JY, Hong YS, Sung YA, Barrett-Connor E. Prevalence and factor analysis of metabolic syndrome in an urban Korean population. Diabetes Care 2004;27:2027-32.

11. Chuang SY, Chen CH, Chou P. Prevalence of metabolic syndrome in a large health check-up population in Taiwan. J Chin Med Assoc 2004;67:611-20.

12. Park HS, Oh SW, Cho SI, Choi WH, Kim YS. The metabolic syndrome and associated lifestyle factors among South Korean adults. Int J Epidemiol 2004;33:328-36.

13. Cameron AJ, Shaw JE, Zimmet PZ. The metabolic syndrome: prevalence in worldwide populations. Endocrinol Metab Clin North Am 2004;33:351-75.

14. Carr MC. The emergence of the metabolic syndrome with menopause. J Clin Endocrinol Metab 2003;88:2404-11.

15. Berenson GS, Srinivasan SR, Bao W, Newman WP, Tracy RE, et al. Association between multiple cardiovascular risk factors and atherosclerosis in children and young adults. $\mathrm{N}$ Engl $\mathbf{J}$ Med 1998;338:1650-6.

16. Orchard TJ, Temprosa M, Goldberg R, Haffner S, Ratner R, Marcovina S, et al. The effect of metformin and intensive lifestyle intervention on the metabolic syndrome: the Diabetes Prevention Program Randomized Trial. Ann Intern Med 2005;142:611-9.

17. Hwang LC, Bai CH, Chen CJ. Prevalence of obesity and metabolic syndrome in Taiwan. J Formos Med Assoc 2006;105: $626-35$.

18. World Health Organization. The Asia-Pacific perspective: redefining obesity and its treatment. WHO: Geneva; 2000.

19. Academic Technology Services in University of California, Los Angeles. Resources to help you learn and use of SUDAAN. Available at: http://www.ats.ulca.edu/stat/sudaan/faq/svy_howto choose.htm. Accessed January 30, 2006.

20. Shen YH, Yang WS, Lee TH, Lee LT, Chen CY, Huang KC. Bright liver and alanine aminotranferase and associated with metabolic syndrome in adults. Obes Res 2005;13:1238-45.
21. Miller WC, Lindeman AK, Wallace J, Niederpruem M. Diet composition, energy intake, and exercise in relation to body fat in men and women. Am J Clin Nutr 1990;52:426-30.

22. Mahoney LT, Burns TL, W Stanford W, Thompson BH, Witt JD, Rost CA, et al. Coronary risk factors measured in childhood and young adult life are associated with coronary artery calcification in young adults: the Muscatine Study. J Am Coll Cardiol 1996;27:277-84.

23. Hoff JA, Chomka EV, Krainik AJ, Daviglus M, Rich S, Kondos GT. Age and gender distribution of coronary artery calcium detected by electron beam tomography in 35,246 adults. Am J Cardiol 2001;87:1335-9.

24. Mittendorfer B. Insulin resistance: sex matters. Curr Opin Clin Nutr Metab Care 2005;8:367-72.

25. Murphy MJ, Metcalf BS, Voss LD, et al. Girls at five are intrinsically more insulin resistant than boys: the programming hypotheses revisited-The EarlyBird Study (EarlyBird 6). Pediatrics 2004;113:82-6.

26. Nuutila P, Knuuti MJ, Maki M, et al. Gender and insulin sensitivity in the heart and in skeletal muscles. Studies using positron emission tomography. Diabetes 1995;44:31-6.

27. Nishizawa H, Shimomura I, Kishida K, et al. Androgens decrease plasma adiponectin, an insulin-sensitizing adipocyte-derived protein. Diabetes 2002;51:2734-41.

28. Wajchenberg BL. Subcutaneous and visceral adipose tissue: their relation to the metabolic syndrome. Endocr Rev 2000;21:697738.

29. Jehn M, Clark JM, Guallar G. Serum ferritin and risk of the metabolic syndrome in US adults. Diabetes Care 2004;27:24228.

30. Punnonen R, Ikalainen M, Seppala E. Premenopausal hysterectomy and risk of cardiovascular disease. Lancet 1987;1:1139.

31. Lin WY, Lee LT, Chen CY, et al. Optimal cut-off values for obesity: using simple anthropometric indices to predict cardiovascular risk factors in Taiwan. Int J Obes Relat Metab Disord 2002;26:1232-8.

32. Ouyang P, Sung J, Kelemen MD, Hees PS, DeRegis JR, Turner $\mathrm{KL}$, et al. Relationships of insulin sensitivity with fatness and fitness in older men and women. J Women's Health 2004;13:17785.

33. Boulé NG, Weisnagel SJ, Lakka TA, Tremblay A, Bergman RN, Rankinen $\mathrm{T}$, et al. Effects of exercise training on glucose homeostasis: the HERITAGE Family Study. Diabetes Care 2005;28:108-14. 